\title{
Evaluation of P wave Dispersion before and after Thrombolytic Therapy
}

\author{
Samir Rafla* and Tarek Elbadawi \\ Department of Cardiology, Alexandria University, Egypt
}

Submission: April 25, 2019; Published: June 04, 2019

*Corresponding author: Samir Rafla, Department of Cardiology, Alexandria University, Egypt

Abstract

Background: P wave dispersion (PWD) constitutes a relatively recent contribution to the field of non-invasive electrophysiology. PWD is defined as the difference between maximum $\mathrm{P}$ wave duration (P max) and minimum $\mathrm{P}$ wave duration (P min) recorded from multiple surface ECG leads.

Methods: The effect of thrombolytic therapy on P wave dispersion was studied in 30 patients (pts) with acute STEMI. Pts received thrombolytic therapy (Streptokinase). Pts were divided into 2 groups; group A: Pts with successful thrombolytic therapy (23) and group B: Pts with failed thrombolytic therapy (7). P wave duration maximum (P max) and minimum (P min) and dispersion were measured. The normal PWD is $28 \mathrm{~ms}+10$. The incidence of arrhythmia was recorded.

Results: PWD was higher in pts with STEMI than normal range. PWD on admission was positively related to age, ST deviation score, CK-MB, Troponin, left atrial size, ejection fraction, and inversely related to beta blocker use before admission and not related to heart rate. No significant difference between sites of infarction as regards PWD. After thrombolytic therapy; PWD and P max were higher in group B than group A: (Gr A $34+6$ vs Gr B $47+10 \mathrm{~ms}, \mathrm{P}<0.006$ ). Arrhythmias during the duration of stay in the ICU were atrial fibrillation in one, ventricular fibrillation in one and $\mathrm{V}$ tachycardia in three. Three pts died.

Conclusion: PWD is correlated with success of thrombolytic therapy and with other parameters as LA size and EF.

Keywords: P wave dispersion; QRS duration; Thrombolytic therapy; Non-invasive electrophysiology; Acute STEMI.

\section{Introduction}

Background: P wave dispersion (PWD) constitutes a relatively recent contribution to the field of non-invasive electrophysiology [1]. PWD is defined as the difference between maximum $P$ wave duration (P max) and minimum $\mathrm{P}$ wave duration (P min) recorded from multiple surface ECG leads.

Aim of the work: The aim of this study was to evaluate the effect of thrombolytic therapy using streptokinase on Pmin, Pmax and PWD and to estimate if there is any special lead distribution of Pmin or Pmax. Also, to evaluate the relation between the severity of STEMI and the extent of PWD in patients with ST segment elevation myocardial infarction.

\section{Methods}

The effect of thrombolytic therapy on P wave dispersion and QRS duration were studied in 30 patients (pts) with acute STEMI. Pts were admitted to the critical care department in Alexandria Main University Hospital. Informed consent was taken from every patient included in the study or from his or her relatives.
Inclusion criteria: 1- Presence of ST segment elevation (at least 1 millivolt) in two contiguous leads anatomically related to certain artery. 2-Absence of contraindications of thrombolytic according to practice guidelines published by the American College of Cardiology and American Heart Association (ACC/AHA) [2]:

Absolute contraindications: 1- History of any intracranial hemorrhage. 2- History of ischemic stroke within the preceding three months, with the important exception of acute ischemic stroke seen within three hours which may be treated with thrombolytic therapy. 3- Presence of a cerebral vascular malformation or a primary or metastatic intracranial malignancy. 4- Symptoms or signs suggestive of an aortic dissection. 5- A bleeding diathesis or active bleeding, with the exception of menses; thrombolytic therapy may increase the risk of moderate bleeding, which is offset by the benefits of thrombolysis.

Exclusion criteria: ECG showing other rhythm then sinus rhythm and presence of one of contraindications of thrombolytic therapy mentioned above. 
After thrombolytic therapy patients were divided into 2 groups according to the response to the therapy:

1) Group A: successful thrombolytic therapy evidenced by [3]:

- More than 50 percent ST segment resolution.

- $\quad$ Resolution of the chest pain

- $\quad$ Presence of reperfusion arrhythmias.

2) Group B: failed thrombolytic therapy evidenced by:

- Less than 50 percent ST segment resolution.

- Persistence of the chest pain.

- $\quad$ Absence of reperfusion arrhythmias.

Methods: All patients were subjected to the following on admission:

1) Clinical evaluation.

2) Electrocardiography: Twelve-lead ECGs of all patients at rest before and one hour after thrombolytic therapy and then twice daily, with $1 \mathrm{mV} / \mathrm{cm}$ amplitude and $50 \mathrm{~mm} / \mathrm{s}$ speed, were obtained. $\mathrm{P}$ wave parameters: The P-wave onset was defined as the first atrial deflection from the isoelectric line and the offset was the return of the atrial signal to baseline. Patients whose measurements could be performed in at least 8 derivations were included in the study. In all patients, derivations were excluded if the beginning or the ending of the $\mathrm{P}$ wave could not be clearly identified. Maximum $\mathrm{P}$ wave duration (Pmax) is defined as the longest and minimum $\mathrm{P}$ wave duration (Pmin) is defined as the shortest $\mathrm{P}$ wave duration. Leads that showed Pmin and Pmax were observed. PWD defined as difference between Pmax and Pmin. All the measurements were repeated three times and average values were calculated for each of electrocardiographic parameter. All of the measurements were performed using the same experienced investigators blind to the subject's clinical status.
Parameters of MI: leads that showed ST segment elevation, number of leads that showed ST segment deviation (elevation or depression), extent of elevation in these leads and ST segment deviation score (the sum of ST segment deviation in all 12 leads).

3) Echocardiographic measurements.

4) Routine laboratory investigations.

The study was approved by the local ethics committee of our institution, and all patients gave written informed consent.

Pts received thrombolytic therapy (Streptokinase) in addition to standard medical therapy. Pts were divided into 2 groups; group A: Pts with successful thrombolytic therapy (23) and group B: Pts with failed thrombolytic therapy (7). P wave duration maximum (P max) and minimum (P min) and dispersion were measured. The normal PWD is $28 \mathrm{~ms}+10$ [4]. QRS duration was measured and pts were divided into 3 groups; Duration $<90 \mathrm{~ms}$, duration 90-110, and duration $>110 \mathrm{~ms}$. The incidence of arrhythmia was recorded.

\section{Results}

Table 1 \& 2 PWD was higher in pts with STEMI than normal range. PWD on admission was positively related to age, ST deviation score, CK-MB, Troponin, left atrial size, ejection fraction, and inversely related to beta blocker use before admission and not related to heart rate. No significant difference between sites of infarction (anterior, inferior, anterior and inferior) as regards PWD. After thrombolytic therapy; PWD and P max were higher in group B than group A: (Gr A $34+6$ vs Gr B $47+10 \mathrm{~ms}, \mathrm{P}<$ 0.006). Arrhythmias during the duration of stay in the ICU were atrial fibrillation in one, ventricular fibrillation in one and $\mathrm{V}$ tachycardia in three. The thrombolytic therapy was successful in 23 patients $(76.6 \%)$ and failed in 7 patients $(23.3 \%)$. We classified the patients according to the outcome of the thrombolytic therapy into two groups: Group (A): patient with successful thrombolysis. Group (B): patient with failed thrombolysis. Three pts died.

Table 1: Relation between PWD and different parameter on admission.

\begin{tabular}{|c|c|c|}
\hline Variable & Applied test & P value \\
\hline Age & $\mathrm{r}=0.891$ & $<0.001$ \\
\hline Heart rate & $\mathrm{r}=-0.259$ & $<0.001$ \\
\hline STDS & $\mathrm{r}=0.896$ & $<0.001$ \\
\hline History of beta-blocker use & $\mathrm{Rho}=-0.609$ & $<0.001$ \\
\hline CKMB & $\mathrm{r}=0.732$ & $<0.001$ \\
\hline Troponin & $\mathrm{r}=0.634$ & $<0.001$ \\
\hline Left atrial size & $\mathrm{r}=0.782$ & 0.002 \\
\hline Ejection fraction & $\mathrm{r}=0.938$ & 0.003 \\
\hline Presence of heart failure & $\mathrm{Rho}=0.411$ & \\
\hline
\end{tabular}

Rho: Spearman coefficient statistically significant at $p<0.05$ : Pearson correlation coefficient. 
Table 2: ECG findings one day after thrombolytic therapy.

\begin{tabular}{|c|c|c|c|}
\hline & \multicolumn{2}{|c|}{ Success of Thrombolysis } & Z (P) \\
\hline Parameter & Yes (group A) 23 patients & N0 (group B) 7 patients & 45 \\
\hline P W Dispersion & 32 & $2.77(0.006)$ & 45 \\
\hline
\end{tabular}

\section{Discussion}

Today, several noninvasive electrocardiographic (ECG) indicators have been investigated to predict the occurrence of arrhythmia. It has been shown, for example, that $\mathrm{P}$ wave dispersion (PWD)-because of its relation to the non-homogenous and interrupted conduction of sinus impulses both intra and interatrially-is a noninvasive indicator that enables the calculation of atrial fibrillation risk on the 12-lead surface ECG [5-8].

It is also known from previous studies that atrial fibrillation occurs in 10 to 15 percent of patients with acute infarction. Its early presence signifies atrial ischemia; later it may also represent atrial stretch caused by increasing filling pressures, that is why it is associated with such an adverse prognosis [9-11].

\section{ECG finding on presentation}

In our study, we found that the average Pmax, Pmin and PWD on presentation were $125.77 \pm 8,83.97 \pm 4.48$ and $41.13 \pm 7.74$ ms respectively and these values was higher than the normal values described in one survey to study the normal range of $\mathrm{P}$ wave parameters in large sample covering almost all age groups of Chinese people, 12-lead surface ECGs were obtained from 2078 healthy Chinese subjects aged between 1 and 87 (mean age $39.4 \pm 17.3$ ) years. The average Pmax, Pmin and PWD in all subjects were $109.9 \pm 7.9,81 \pm 11.4$ and $28.9 \pm 10.7$ ms respectively [5].

We also found that there is a strong positive correlation between Pmax and the age of the studied patients $(\mathrm{P}<0.001)$ and also between $\mathrm{PWD}$ and the age $(\mathrm{P}<0.001)$. The Chinese study also revealed that there was a progressive increase in the mean value of Pmax, Pmin and PWD with age [5].

We did not find any specific lead distribution of Pmin or Pmax in the studied patients, but the previous study found that most Pmax was found in lead II (77.0\%) or V5 (14.3\%). Whereas most Pmin was found in lead VI (74.7\%) or V2 (7.8\%).

In a study to evaluate the effects of myocardial ischemia on $\mathrm{P}$ dispersion and $\mathrm{P}$ maximum. 95 patients with coronary artery disease (CAD) and typical angina pectoris and 15 controls with angina like symptoms underwent 12-lead surface ECG during and after the relief of pain. During pain and during the asymptomatic period, $\mathrm{P}$ maximum and $\mathrm{P}$ dispersion were calculated from the averaged complexes of all 12 leads, it found that only P wave dispersion was significantly higher during the anginal episode compared to the asymptomatic period in both patient groups with or without prior MI. P maximum and P dispersion were not significantly different between patients and controls during the asymptomatic recording, while they were both significantly higher in patients than in controls during pain $(\mathrm{P}=0.048$ and $\mathrm{P}=$
0.037 , respectively). P minimum was not found to differ between patients and controls in the symptomatic nor in the painless period. During the anginal episode, both $\mathrm{P}$ dispersion and $\mathrm{P}$ maximum were found to be significantly higher in those patients who showed ST segment changes (depression or elevation) in both lead groups (II, III, aVF, and I, aVL, V2-V6) compared to those patients who showed ST segment alterations in only one of the two lead groups [11-19].

Thus, we agree with this study in that:

- $\quad$ During attacks of myocardial ischemia, Pmax and PWD are larger than normal.

- PWD was positively correlated with the extent of myocardial ischemia.

- We found that there was no significant difference in PWD as regard site of infarction (anterior, inferior or anterior and inferior).

- On examination, we found 3 patients with signs of heart failure. By applying statistical tests, we found that PWD was higher in these patients.

\section{Echocardiographic findings in first day of admission}

We also found that PWD was significant positive correlation between $\mathrm{PWD}$ and both left atrial size $(\mathrm{P}<0.001)$ and left ventricular ejection fraction $(\mathrm{P}=0.02)$ in the first day of hospitalization.

Dilaveris P, et al. [11] studied the effects of myocardial ischemia on $\mathrm{P}$ dispersion and $\mathrm{P}$ maximum. 95 patients with coronary artery disease (CAD) and typical angina pectoris and 15 controls with angina like symptoms and found that $P$ dispersion was significantly higher in patients with left ventricular dysfunction (EF < 45\%) than in patients with preserved left ventricle function $(\mathrm{EF}>$ $45 \%)$ during angina $(\mathrm{P}=0.032)$, but not in painless conditions. Univariate analysis of variances showed that during the anginal episode, P dispersion was significantly higher in patients with left ventricular dysfunction, independent of the presence of previous MI [11].

\section{Drug history}

In our study, twenty-two (73.3\%) patients were receiving beta-blocker and ten (33.3\%) patients were receiving ACE inhibitor.

We found that PWD was positively correlated with the use of beta blocker $(\mathrm{P}<0.001)$ and ACE inhibitors ( $\mathrm{P} 0.001)$ so, patients on beta blockers or ACE inhibitors before presentation had smaller PWD. Korkmaz H et al. [17] studied the effect of nebivolol and quinapril on P-wave duration and dispersion in newly diagnosed 
hypertensive patients, the study group consisted of 54 patients (Mean age: $53 \pm 9$ years, $46 \%$ women) with 27 patients in each group patients who were assigned to the two treatment groups and received either $20 \mathrm{mg}$ quinapril/day or $5 \mathrm{r}$ mg nebivolol/day. P-Wave dispersion (PWD) was measured at baseline and after four weeks of treatment. Both groups showed a similar but significant reduction in PWD and Pmax. The delta PWD was $-16 \pm 14 \mathrm{~ms}(\mathrm{P}$ $0.000 \mathrm{l})$ and $-13 \pm \mathrm{ll} \mathrm{ms}$, (P0.000l) in the nebivolol and quinapril group, respectively. Corresponding figure for Pmax was $-10 \pm 11$ ms $(\mathrm{P}=0.001)$ and $-9 \pm 11 \mathrm{~ms}(\mathrm{P}=0.001)$, respectively. This effect was independent of blood pressure and heart rate changes [17].

Investigations on presentation: In our study we found significant positive correlation between PWD and both Troponin $\mathrm{T}(\mathrm{P}<0.001)$ and $\mathrm{CK}$ MB $(\mathrm{P}$ 0.00l) on presentation. A similar correlation of the degree of troponin elevation with mortality was seen in the TIMI IIIB trial, the GUSTO Ha trial, and the FRISC study [20].

In our study we found a strong positive correlation between ST segment deviation score (STD score) before thrombolytic therapy and PWD $(\mathrm{P}<0.001)$. the importance of STD score was shown in a multivariate analysis from the GUSTO-I database of 41,021 patients it was found that The number of ECG leads showing ST segment deviation (elevation or depression) and the ST segment deviation score (using the sum of ST segment deviation in all 12 leads) are markers for the extent' of the ischemic area in acute coronary syndromes [21]. Thus, the extent of PWD can reflect the severity of MI.

\section{Conclusion}

PWD is correlated with success of thrombolytic therapy and with other parameters as LA size and EF. There is no conflict of interest.

\section{References}

1. Hassell TA, Hoffbrand BI (1970) P wave abnormalities with myocardial infarction: an aid to the diagnosis of left ventricular failure. Postgrad Med J 46(537): 428-429.

2. Dilaveris PE, Gialafos EJ, Sideris SK, Theopistou AM, Andrikopoulos GK, et al. (1998) Simple electrocardiographic markers for the prediction of paroxysmal idiopathic atrial fibrillation. Am Heart J 135(5 Pt 1): 733738.

3. Koide Y, Yotsukura M, Sakata K, Yoshino H, Ishikawa K (2002) Investigation of the predictors of transition to persistent atrial fibrillation in patients with paroxysmal atrial fibrillation. Clin Cardiol 25(2): 69-75.

4. Guray U, Guray Y, Yýlmaz MB, Mecit B, Sasmaz H, et al. (2003) Evaluation of $\mathrm{P}$ wave duration and $\mathrm{P}$ wave dispersion in adult patients with secundum atrial septal defect during normal sinus rhythm. Int J Cardiol 91(1): 75-79.

5. Dogan SM, Yildirim N, Aydin M, Gursurer M, Cam F, et al. (2008) Assessment of P-wave duration and dispersion in patients with isolated coronary artery ectasia. Int J Cardiol 125(3): 404-406.
6. Soylu M, Demir AD, Ozdemir O, Soylu O, Topaloğlu S, et al. (2004) Increased $\mathrm{P}$ wave dispersion after the radiofrequency catheter ablation in overt pre-excitation patients: the role of atrial vulnerability. Int J Cardiol 95(2-3): 167-170.

7. Myrianthefs MM, Shandling AH, Startt-Selvester RH, Bernstein SB, Crump R, et al. (1992) Analysis of the signal-averaged P-wave duration in patients with percutaneous coronary angioplasty-induced myocardial ischemia. Am J Cardiol 70(7): 728-732.

8. Dilaveris PE, Andrikopoulos GK, Metaxas G, Richter DJ, Avgeropoulou CK, et al. (1999) Effects of Ischemia on P Wave Dispersion and Maximum P Wave Duration during Spontaneous Anginal Episodes. Pacing Clin Electrophysiol 22(11): 1640-1647.

9. Rosiak M, Bolinska H, Ruta J (2002) P wave dispersion and P wave duration on SAECG in predicting atrial fibrillation in patients with acute myocardial infarction. Ann Noninvasive Electrocardiol 7(4): 363368.

10. Akdemir R, Ozhan H, Gunduz H, Tamer A, Yazici M, et al. (2005) Effect of reperfusion on P-wave duration and P-wave dispersion in acute myocardial infarction: primary angioplasty versus thrombolytic therapy. Ann Noninvasive Electrocardiol 10(1): 35-40.

11. Dilaveris PE, Andrikopoulos GK, Metaxas G, Richter DJ, Avgeropoulou CK, et al. (2006) Effects of Ischemia on P Wave Dispersion and Maximum P Wave Duration During Spontaneous Anginal Episodes.

12. Baykan M, Celik S, Erdöl C, Durmuş I, Orem C, et al. (2003) Effects of P-wave Dispersion on Atrial Fibrillation in Patients with Acute Anterior Wall Myocardial Infarction. Ann Noninvasive Electrocardiol 8(2): 101-106.

13. Nilay S, Paltial P, Shivkumar M, Manish P, Dilip M (2014) ST-SEGMENT RESOLUTION: A CRITERION OF SUCCESSFUL THROMBOLYSIS IN ACUTE MYOCARDIAL INFARCTION. IJCRR 6(9): 99-108.

14. Batur MK, Yildirir A, Onalan O, Kabakci G, Tokgozoglu L, et al. (2002) Angioplasty induced myocardial ischaemia prolongs the signalaveraged P-wave duration in single vessel coronary artery disease. Europace 4(3): 289-293.

15. Hancock JE, Cooke JC, Chin DT, Monaghan MJ (2018) Determination of Successful Reperfusion After Thrombolysis for Acute Myocardial Infarction. Circulation 105(2): 157-161.

16. Camsari A, Pekdemir H, Akkus MN, Yenihan S, Döven O, et al. (2003) Long-term effects of beta blocker therapy on P-wave duration and dispersion in congestive heart failure patients: a new effect? J Electrocardiol 36(2): 111-116.

17. Korkmaz H, Onalan O, Akbulut M, Ozbay Y (2009) Nebivolol and quinapril reduce p-wave duration and dispersion in hypertensive patients. Indian Pacing and Electrophysiology Journal 9(3): 158-166.

18. Fatih A, Inci F, Fahrettin K (2014) P-wave dispersion and its relationship with the severity of the disease in patients with stable coronary artery disease. North Clin Istanbul 1(2): 65-70.

19. Chen Y, Nie S, Gao H, Sun T, Liu X, et al. (2013) The Effects of Wenxin Keli on P-Wave Dispersion and Maintenance of Sinus Rhythm in Patients with Paroxysmal Atrial Fibrillation: A Meta-Analysis of Randomized Controlled Trials. Evid Based Complement Alternat Med 2013: 245958.

20. Lagerqvist B, Diderholm E, Lindahl B, Husted S, Kontny F, et al. (2005) FRISC score for selection of patients for an early invasive treatment strategy in unstable coronary artery disease. Heart 91(8): 1047-1052.

21. Armstrong PW, Fu Y, Chang WC, Topol EJ, Granger CB, et al. (1998) Acute Coronary Syndromes in the GUSTO-IIb Trial. Prognostic Insights and Impact of Recurrent Ischemia. Circulation 98(18): 1860-1868. 


Your next submission with Juniper Publishers
will reach you the below assets
- Quality Editorial service
- Swift Peer Review
- Reprints availability
- E-prints Service
- Manuscript Podcast for convenient understanding
- Global attainment for your research
- Manuscript accessibility in different formats
( Pdf, E-pub, Full Text, Audio)
- Unceasing customer service
Track the below URL for one-step submission
https://juniperpublishers.com/online-submission.php

